\title{
A Simple Method of Discriminating between Occurrences of Freezing Rain and Ice Pellets in the Kanto Plain, Japan
}

\author{
Hiroki MATSUSHITA \\ Civil Engineering Research Institute for Cold Region, Sapporo, Japan \\ and \\ Fumihiko NISHIO \\ Center for Environmental Remote Sensing, Chiba University, Chiba, Japan
}

(Manuscript received 26 April 2007, in final form 4 June 2008)

\begin{abstract}
Based on a freezing rain and ice pellet event observed on 3 January 2003 in the Kanto Plain, Japan, the atmospheric conditions necessary for the occurrence of such phenomena in this area were investigated, and a simple method of discriminating precipitation types, including freezing rain and ice pellets, was examined.

Freezing rain and ice pellets fell from 1800 to 2400 JST on 3 January in the western portion of the Kanto Plain. During the precipitation, northwesterly cold-air advection near the surface dominated in this region, with southerly warm-air advection associated with the approach of a synoptic low present above the cold air layer. This atmospheric structure produced the conditions required for freezing rain and ice pellets to form, namely a melting layer with an air temperature above $0^{\circ} \mathrm{C}$ to melt snow particles into raindrops, and a refreezing layer with an air temperature below $0^{\circ} \mathrm{C}$ to supercool the raindrops into freezing rain or freeze them into ice pellets.

To establish a method of discriminating between freezing rain and ice pellets, the conditions required for the complete melting of snow particles and the complete freezing of raindrops during the event were examined theoretically. We found that the mean air temperatures, the mean relative humidities, and the depths of the melting and refreezing layers can be used to distinguish the environmental conditions required for freezing rain and ice pellets to form. In addition, determination of whether the wet-bulb temperature at the surface is above or below $0^{\circ} \mathrm{C}$ was used to discriminate rain and freezing rain. The distribution of precipitation types at 2100 JST on 3 January 2003 in the Kanto Plain was estimated using the method described above, and the results agreed closely with the distribution actually observed. The diagnostic method presented in this study enables the discrimination of precipitation types, including freezing rain and ice pellets.
\end{abstract}

\section{Introduction}

Ice pellets, defined as transparent solid precipitation, and freezing rain, defined as liquid precipita-

Corresponding author: Hiroki Matsushita, Civil Engineering Research Institute for Cold Region, Hiragishi 1-3-1-34, Toyohira-ku, Sapporo 062-8602, Japan E-mail: hmatsu@ceri.go.jp

(C)2008, Meteorological Society of Japan tion in a supercooled state, were observed on 3 January 2003 in Musashino City in the southwestern portion of the Kanto Plain, Japan. In the northern portion of the plain, including the boundary region between Saitama and Gunma Prefectures, about $50 \mathrm{~km}$ of overhead wires for railways were covered with transparent ice (called glaze) of a few centimeters thick due to freezing rain. Because rail service was halted for many hours, about a 
thousand people remained stranded in their trains all night and a total of 48,000 people did not reach their destinations. The glaze phenomenon due to freezing rain will have a large impact on this highpopulation region, which does not frequently experience serious snow and ice disasters.

In general, for freezing rain to occur, it is necessary that a warm air layer exists to melt snow particles into raindrops and that a lower cold air layer supercools the descending raindrops near the ground (Fig. 1). Ice pellets are formed when raindrops refreeze before reaching the ground. This vertical atmospheric structure has been known for a long time (e.g., Okada 1914; Meisinger 1920) and is referred to as the "ice-melting process". In addition, even if the air temperature is below $0^{\circ} \mathrm{C}$, supercooled water drops grow through the "warm rain process (collision coalescence process)". Freezing drizzle, which has smaller diameter than that of raindrops, forms most often through the warm rain process (e.g., Bocchieri 1980; Huffman and Norman 1988; Cober et al. 1996; Rauber et al. 2000). The melting process plays an important role in glaze formation due to the freezing rain that occurs at ground level.

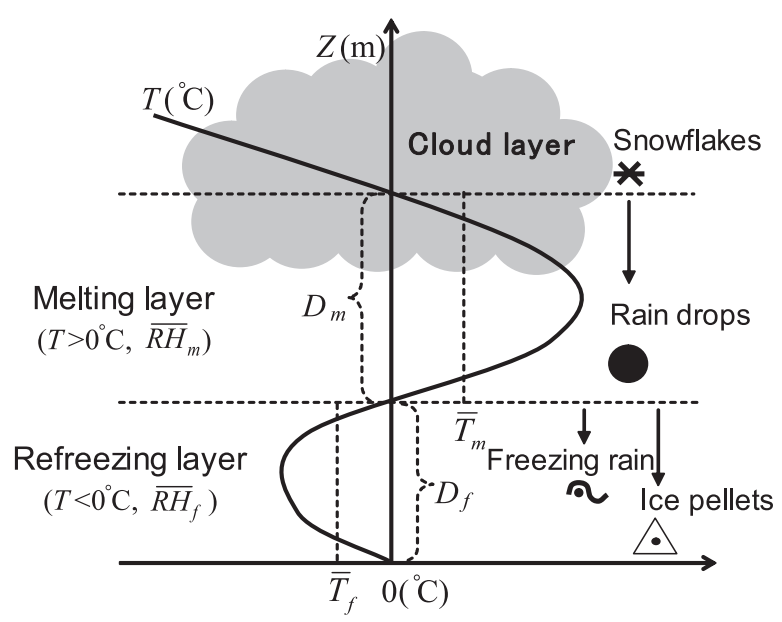

Fig. 1. Schematic diagram portraying the atmospheric conditions for the occurrence of freezing rain and ice pellets. $\bar{T}_{m}$ and $\bar{T}_{f}$ are the mean air temperatures, $\overline{R H}_{m}$ and $\overline{R H}_{f}$ are the mean relative humidities, and $D_{m}$ and $D_{f}$ are the depths of the melting and refreezing layers. These parameters are used to discriminate between freezing rain and ice pellets (see Section 4).
Glaze formed by freezing rain causes many problems such as traffic accidents, fallen trees, and power failures. Freezing rain and glaze events occur most frequently in the eastern region of North America (Cortinas et al. 2004; Changnon and Karl 2003). In this region, local meteorological influences on the freezing rain (Bernstein 2000) and the synoptic characteristics (Rauber et al. 2001a; Robbins and Cortinas 2002) associated with freezing rain events have been studied well. In Japan, most of the freezing rain and ice pellet events occur in the inland ravines and plains on the Pacific Ocean side of northern central Japan, with a frequency of about once every five years (Matsushita and Nishio 2004), and the disasters due to glaze occur in the same region (Ushiyama 1991). In the Kanto Plain, freezing rain and glaze have been reported since the early twentieth century. For example, Okada (1914) reported a glaze phenomenon observed in Tokyo on 8 January 1902, with an air temperature below $0^{\circ} \mathrm{C}$. The air temperature at the summit of Mt. Tsukuba (elevation $870 \mathrm{~m}$ ), located about $60 \mathrm{~km}$ north of Tokyo, was above $0^{\circ} \mathrm{C}$. Thus, the atmospheric conditions required for freezing rain to occur had been established. However, the formation process of this atmospheric structure, based on local meteorology, has not been investigated, and there is insufficient information for forecasting freezing rain in this region.

For improved forecasting of freezing rain and ice pellets, the atmospheric conditions necessary for these precipitation types have been well examined by many previous studies focused on the air temperature, depth, and height of the melting and refreezing layers (e.g., Zerr 1997; Rauber et al. 2000; Robbins and Cortinas 2002; Hux et al. 2001). Furthermore, diagnostic methods for distinguishing freezing rain and ice pellets, based on thermodynamic theory involving the interaction between precipitation particles and the environmental air, were developed by Ishihara and Tadokoro (1990), Czys et al. (1996), and Stewart and King (1987) for the melting of snow particles, and by Stewart et al. (1990) for the refreezing of melted snow particles. Although conditions in the melting and refreezing layers were individually evaluated in these studies, both conditions have to be examined for forecasting of freezing rain and ice pellets.

Zerr (1997) examined the conditions necessary for both the melting and refreezing of precipitation particles using theoretical models including the heat balance between particles and its environmen- 
tal air. In these calculations, however, the vertical profiles of air temperatures between the levels at the maximum air temperature in the melting layer and the minimum air temperature in the refreezing layer were estimated by assuming a constant adiabatic lapse rate, and the latent heat arising from changes in water state at the surface of the precipitation particles was neglected. The examination was therefore different from the actual atmospheric conditions found when freezing rain and ice pellets form. As thermodynamic indices for the melting and refreezing layers, it is preferable to use thermal capacities or integration of the air temperature obtained from the vertical profile.

Bourgouin (2000) indicated statistical discrimination between freezing rain and ice pellets using the thermal capacities of both the melting and refreezing layers. However, the study supposed saturated air conditions in the melting and refreezing layers. The latent heat effect caused by the moisture in the air also affects the melting and freezing processes of precipitation particles (Matsuo and Sasyo 1981b; Mitra et al. 1990; Pruppacher and Klett 1997) and consequently influences the determination of precipitation types at ground level. Recently, a simulation of winter precipitation types, including freezing rain and ice pellets, was developed by applying a microphysical model representing complex processes in clouds (Thériault et al. 2006).
In this paper, a diagnostic method of discriminating precipitation types, including freezing rain and ice pellets, will be investigated using the case observed on 3 January 2003 in the Kanto Plain. The concepts to be considered are: (1) examination of conditions in both the melting and refreezing layers, (2) consideration of the effects of latent heat on the melting and refreezing of precipitation particles, and (3) the use of simple indices that can be easily obtained from routine observation of upper air soundings.

\section{Data}

Figure 2 depicts the topography of the Kanto Plain and the locations of the meteorological observing stations in this region. The Kanto Plain is the largest plain in Japan and is adjoined by mountain areas to the north and west, while its southern and eastern portions face the Pacific Ocean. There are many large cities in this plain, including Tokyo, Saitama, and Yokohama, and about 40 million people (one third of Japan's population) lives there.

The analyses in this paper are based on surface meteorological data, aerological data, and mesoscale objective analysis data, provided on CD-ROM by the Japan Meteorological Agency (JMA). The meteorological stations for observing the surface and upper air are presented in Fig. 2. The time

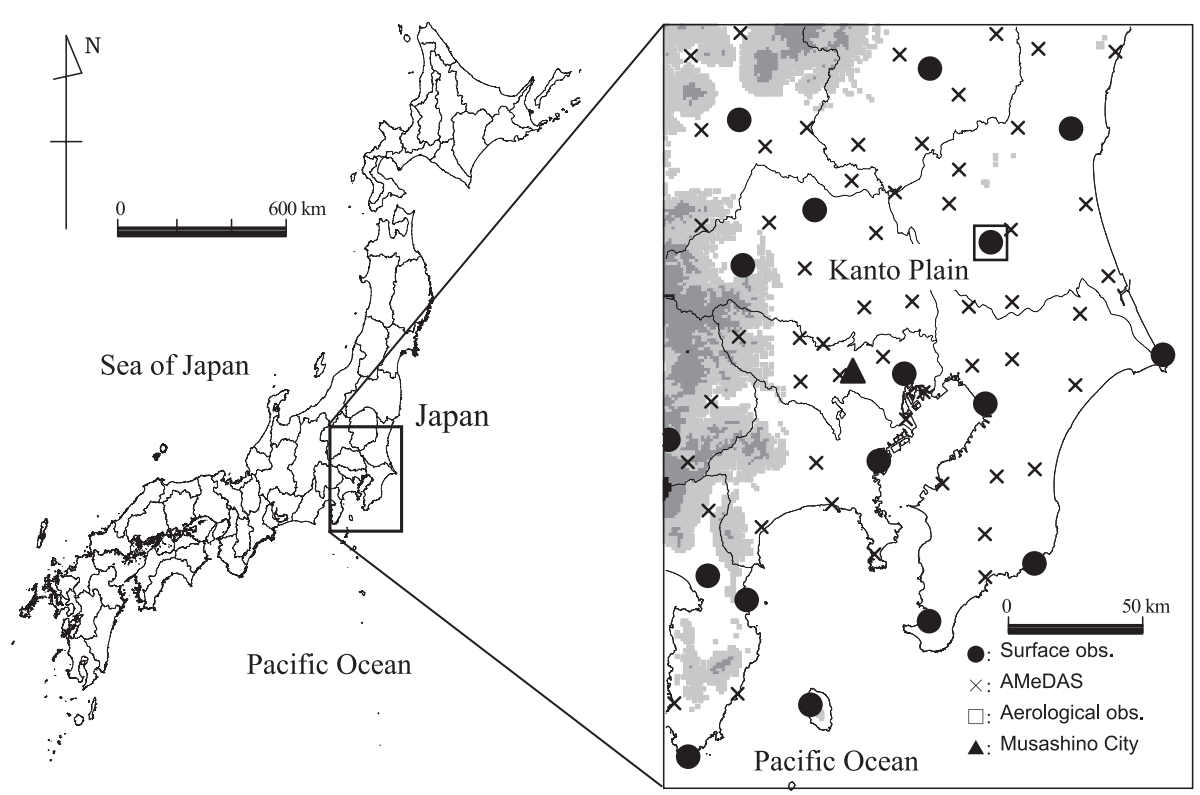

Fig. 2. Topography and location of meteorological observing stations in the Kanto Plain. 
used in this paper is Japan Standard Time (JST), which is 9 hours ahead of universal time (UT).

The surface meteorological data consists of observations from weather stations and from the Automated Meteorological Data Acquisition System (AMeDAS) of JMA, and includes the air temperature, amount of precipitation, wind velocity, and wind direction, compiled at one-hour intervals. At the weather stations, the air pressure and relative humidity were also observed, and the wet-bulb temperature and equivalent potential temperature were obtained from these data. In addition, precipitation types such as rain, snow, freezing rain, and ice pellets are recorded by eye observation at the weather stations. Observations of precipitation types in Musashino City, located in the southwestern portion of the Kanto Plain (Fig. 2), were carried out by authors.

The aerological data used in this study was obtained at Tateno, the only upper air observation station in the plain. The data includes the air temperature, relative humidity, and wind at significant pressure levels of the upper air as observed by radiosonde soundings taken twice per day (0900 JST and 2100 JST). The mesoscale objective analysis data includes the same meteorological elements as the aerological data at the standard pressure levels (e.g., at heights of 950, 900, and $850 \mathrm{hPa}$ ) over grid points on a $10 \mathrm{~km}$ mesh, and is taken at $0300,0900,1500$, and 2100 JST. To investigate the upper-air conditions over a surface observing sta-
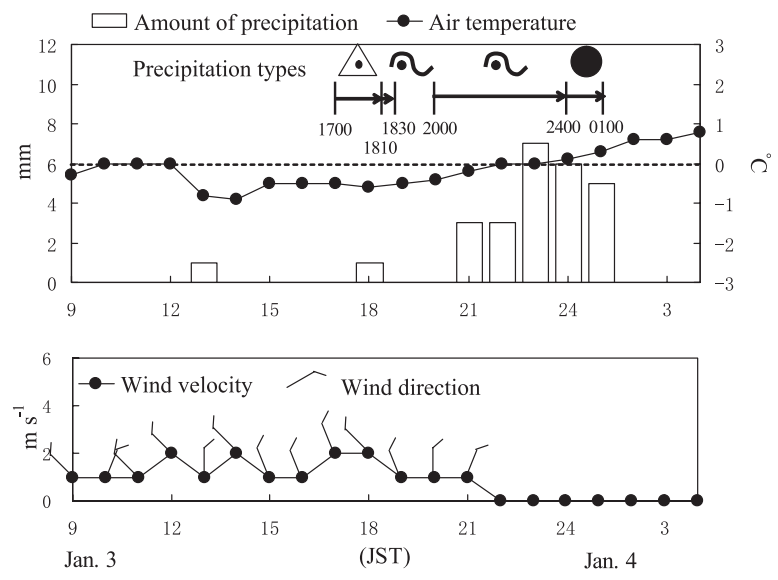

Fig. 3. Precipitation types at Musashino City and air temperature, amount of precipitation, and wind at Fuchu on 3-4 January 2003. tion, we used the objective data for the grid point nearest to that station.

The altitude above sea level of each station and grid point was obtained from the Digital Elevation Model (DEM) compiled by the Geographical Survey Institute of Japan. The DEM consists of elevations above sea level on a grid with latitude intervals of 1.4" and longitude intervals of 2.25", corresponding to about $50 \mathrm{~m}$ by $50 \mathrm{~m}$.

\section{Characteristics of freezing rain and ice pellets on 3 January 2003}

\subsection{Weather conditions at Musashino City}

Figure 3 shows the precipitation types observed at Musashino City and the air temperature, amount of precipitation, and wind conditions observed at Fuchu of AMeDAS, located about $5 \mathrm{~km}$ southwest of Musashino City. In the afternoon of 3 January 2003, it had been snowing intermittently in Musashino City since the morning, and ice pellets began to fall at 1700 JST. Most of the ice pellets were transparent spherical ice with a diameter of about $2 \mathrm{~mm}$ (Fig. 4). The ice pellets fell intermittently until they changed to rain at 1810 JST. The rain was regarded as freezing rain because the air temperature at the surface was below $0^{\circ} \mathrm{C}$ and transparent ice and icicles, called glaze, formed on trees and other objects. The freezing rain stopped falling at 1830 JST and began to fall once again at 2000 JST. Because the glaze remained until the air

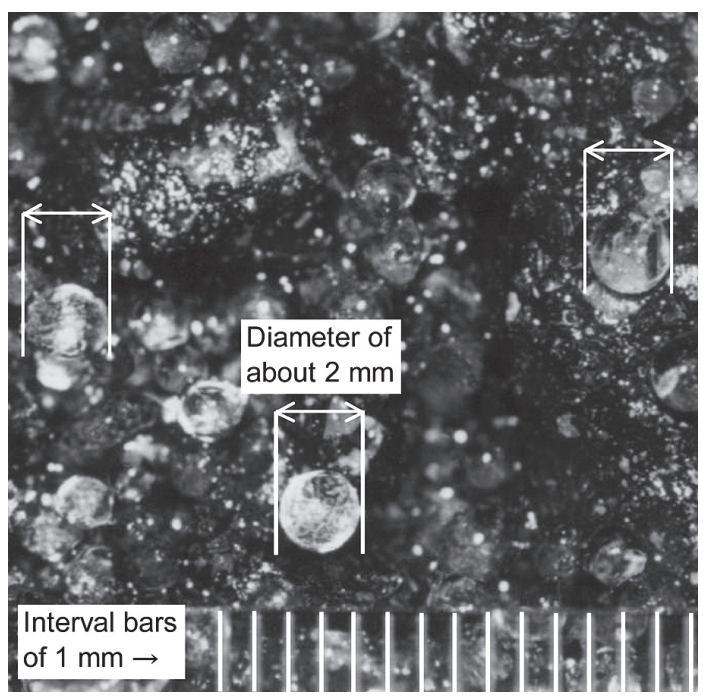

Fig. 4. Ice pellets observed at Musashino City at 1800 JST on 3 January 2003. 
temperature rose above $0^{\circ} \mathrm{C}$ at $2400 \mathrm{JST}$, the freezing rain would be changing to rain at this time.

While the freezing rain and ice pellets were falling, the air temperature gradually increased from $-5^{\circ} \mathrm{C}$, the precipitation intensity ranged from 1 to $3 \mathrm{~mm} \mathrm{~h}^{-1}$, and the wind velocity was about $1 \mathrm{~m} \mathrm{~s}^{-1}$ with wind direction from northwest or north, but calm conditions were observed after 2200 JST.

\subsection{Mesoscale conditions in the Kanto Plain}

Figure 5 indicates the precipitation types observed at 1800, 2100, and 2400 JST on 3 January in the Kanto Plain. At 1800 JST, ice pellets were observed at Kofu and Musashino City, and at 2100 JST, freezing rain fell at Musashino City and ice pellets were also recorded at Kumagaya. Figure 5 also indicates the times at which wind observations were disturbed due to a frozen anemometer. In Kumagaya, while the anemometer was freezing

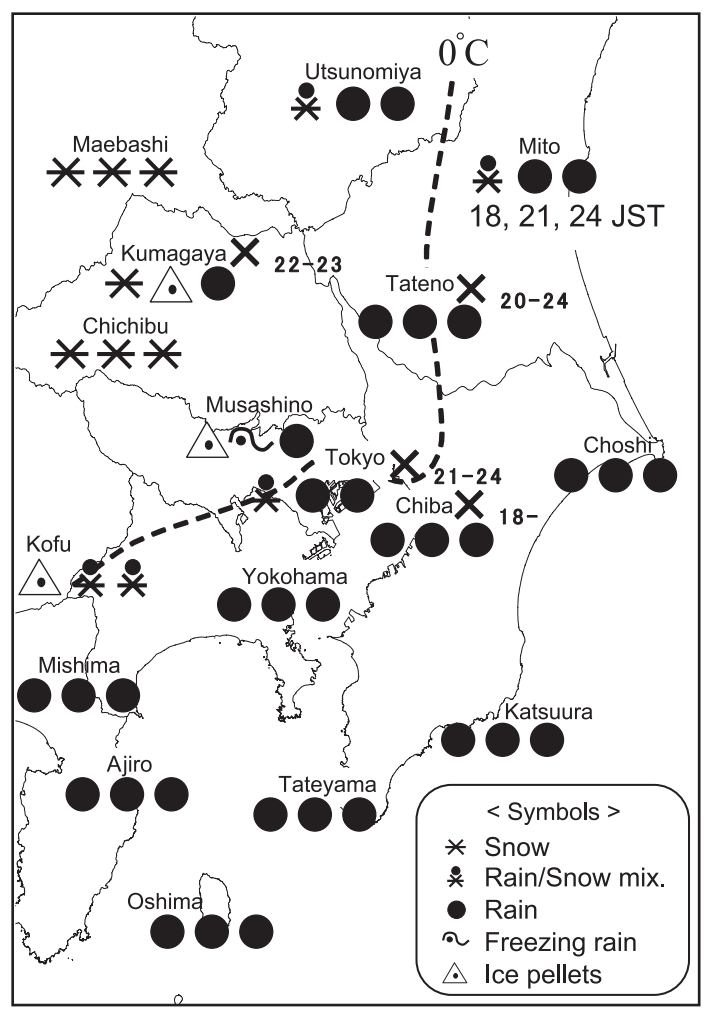

Fig. 5. Distribution of precipitation types at 1800,2100 , and 2400 JST and the isothermal line for $0^{\circ} \mathrm{C}$ at 1800 JST in the Kanto Plain. Crosses and their related numbers represent stations with frozen anemometers and the time of occurrence.
(2200 to 2300 JST), rain was recorded with a surface air temperature below $0^{\circ} \mathrm{C}$, so freezing rain caused the freezing of the anemometer. At Tateno, Tokyo, and Chiba, surface air temperatures were slightly above $0^{\circ} \mathrm{C}$ when wind observations were disturbed. However, the wet-bulb temperatures at these stations were below $0^{\circ} \mathrm{C}$, and the air temperature at the height of the anemometers, evaluated by using a lapse rate of $0.64^{\circ} \mathrm{C}$ per $100 \mathrm{~m}$ observed on $2100 \mathrm{JST}$ at Tateno, was below $0^{\circ} \mathrm{C}$. At the height of the anemometers, therefore, freezing rain would also cause a disturbance in the wind observations at these stations.

In Fig. 5, a comparison of the distribution of precipitation types and the location of the $0^{\circ} \mathrm{C}$ isothermal line at the surface shows that rain and snow were observed separately in the region whether the air temperature was above or below $0^{\circ} \mathrm{C}$, and that freezing rain and ice pellets were observed with air temperatures below $0{ }^{\circ} \mathrm{C}$ in the transition region between rain and snow. Anemometers froze due to freezing rain near the isothermal line of $0^{\circ} \mathrm{C}$.

\subsection{Characteristics of atmospheric structure}

Figure 6 is a surface weather map at 2100 JST on 3 January. Two lows are located in the Sea of Japan and on the southern coast of Japan, and are moving to the northeast.

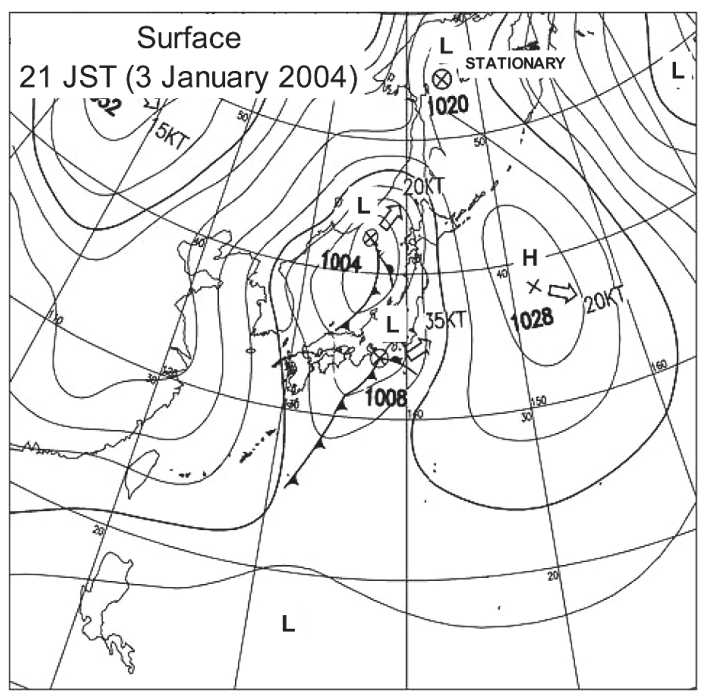

Fig. 6. Surface weather map at 2100 JST on 3 January 2003 provided by the Japan Meteorological Agency (JMA). 

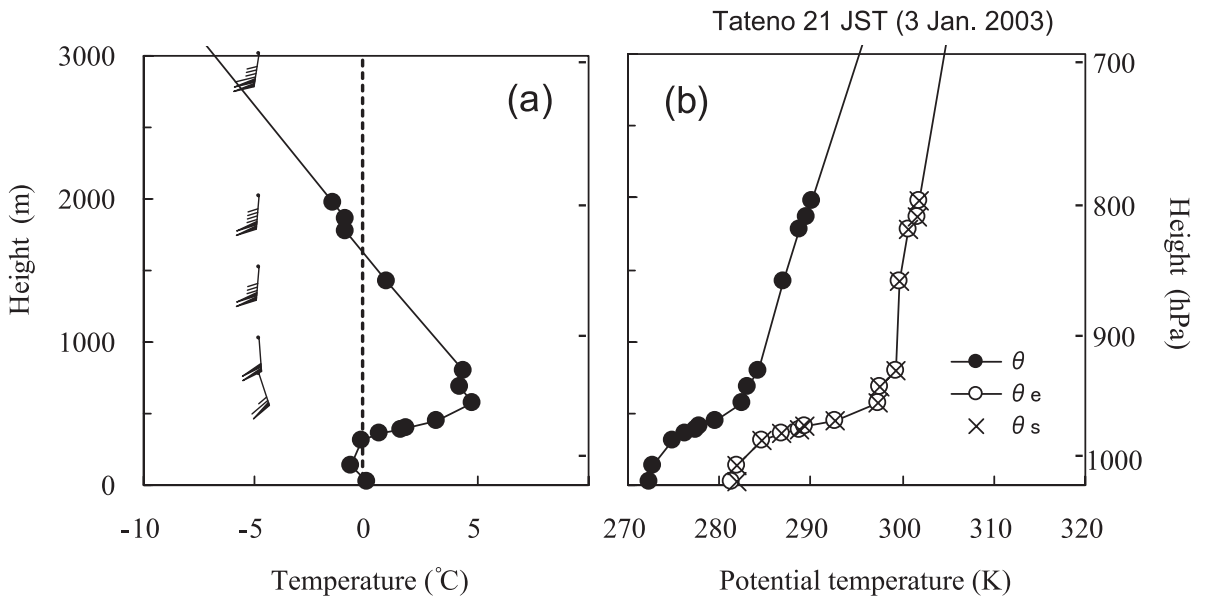

Fig. 7. Vertical profiles of (a) air temperature and wind, (b) potential temperature $\theta$, equivalent potential temperature $\theta_{e}$, and saturated equivalent potential temperature $\theta_{s}$ at Tateno at 2100 JST on 3 January 2003. In (a), half barbs denote $1 \mathrm{~m} \mathrm{~s}^{-1}$, full barbs $5 \mathrm{~m} \mathrm{~s}^{-1}$, and pennants $10 \mathrm{~m} \mathrm{~s}^{-1}$.

Figure 7 presents vertical profiles of the air temperature, wind, and potential temperatures at Tateno at 2100 JST on 3 January. The entire atmospheric layer below a height of about $3000 \mathrm{~m}$ was saturated. A warm air layer to melt the snow particles in which the air temperature was above 0 ${ }^{\circ} \mathrm{C}$ (hereafter called the melting layer) existed at a height of 400 to $1600 \mathrm{~m}$ with a depth of $1200 \mathrm{~m}$, with a strong southerly wind of over $20 \mathrm{~m} \mathrm{~s}^{-1}$ dominating the layer. A cold air layer in which the air temperature was below $0^{\circ} \mathrm{C}$ (hereafter called the refreezing layer) existed below the melting layer. Thus, the environmental conditions necessary for forming of freezing rain were established around this time.

Figure 8 shows the distribution of the equivalent potential temperature, wind condition, and the $0^{\circ} \mathrm{C}$ isothermal line at $900 \mathrm{hPa}$, corresponding to the height of the melting layer seen in Fig. 7. Strong southerly warm advection dominated widely over the Kanto Plain, and the $0^{\circ} \mathrm{C}$ isothermal line

Fig. 8. Distribution of equivalent potential temperature, wind, and the isothermal line for $0^{\circ} \mathrm{C}$ at $900 \mathrm{hPa}$ over the Kanto Plain at 2100 JST on 3 January 2003 obtained from JMA mesoscale objective analysis data. Broken lines represent the equivalent potential temperature with an interval of $4 \mathrm{~K}$, while the solid line is the isothermal line for $0^{\circ} \mathrm{C}$. Half barbs denote $1 \mathrm{~m} \mathrm{~s}^{-1}$, full barbs $5 \mathrm{~m} \mathrm{~s}^{-1}$, and pennants $10 \mathrm{~m} \mathrm{~s}^{-1}$. reached the northern portion of the plain. Therefore, the melting layer over the Kanto Plain was formed by strong warm advection associated with approaching surface lows as seen in Fig. 6. In addition, comparing Fig. 5 with Fig. 8 indicates that freezing rain and ice pellets were observed in the

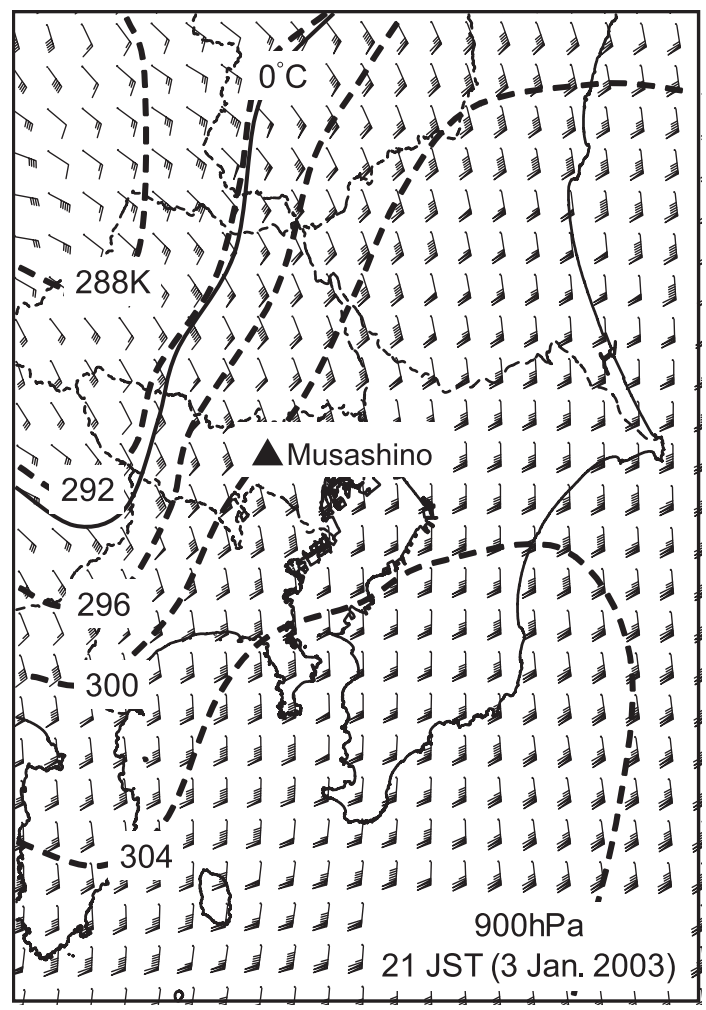


region between the $0^{\circ} \mathrm{C}$ isothermal line at the surface and the one at $900 \mathrm{hPa}$ pressure level.

To clarify the air flow near the surface, Fig. 9 shows the surface distribution of the equivalent potential temperature and the wind conditions at

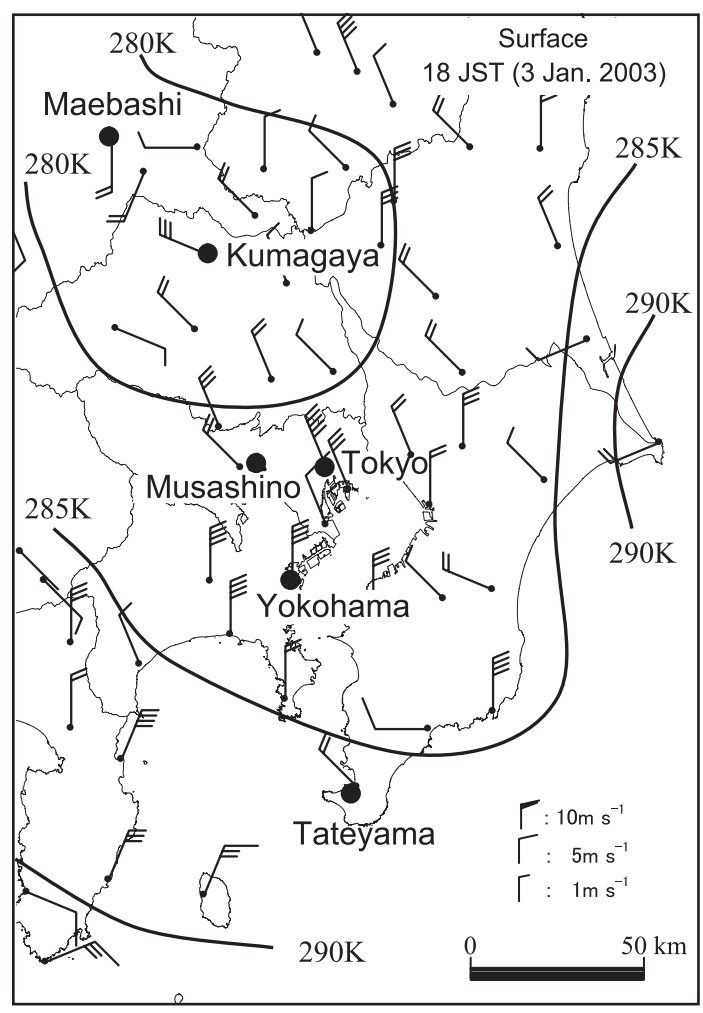

1800 JST, when freezing rain and ice pellets began to fall at each station. At the surface of the Kanto Plain, northwesterly cold air advection from an inland mountainous region toward the southern coastal region dominated the western portion of the plain, and continued to flow as freezing rain and ice pellets were falling by 2400 JST. Consequently, the local cold advection from the inland region formed the refreezing layer near the surface seen in Fig. 7.

\section{Discrimination between freezing rain and ice pellets}

\subsection{Concept of discrimination}

Figure 10 compares the vertical profiles of air temperature and dew point and the precipitation types observed at each station on the Kanto Plain at 2100 JST on 3 January. Refreezing layers with air temperatures below $0^{\circ} \mathrm{C}$ near the surface developed in inland regions such as Kumagaya, and melting layers above $0^{\circ} \mathrm{C}$ over the southern regions such as Yokohama were thicker than those in the northern regions. The melting layer was

Fig. 9. Distribution of equivalent potential temperature and wind at the surface at 1800 JST on 3 January 2003. Solid lines depict the equivalent potential temperature with an interval of $5 \mathrm{~K}$. Half barbs denote $1 \mathrm{~m} \mathrm{~s}^{-1}$, full barbs $5 \mathrm{~m} \mathrm{~s}^{-1}$, and pennants $10 \mathrm{~m} \mathrm{~s}^{-1}$.
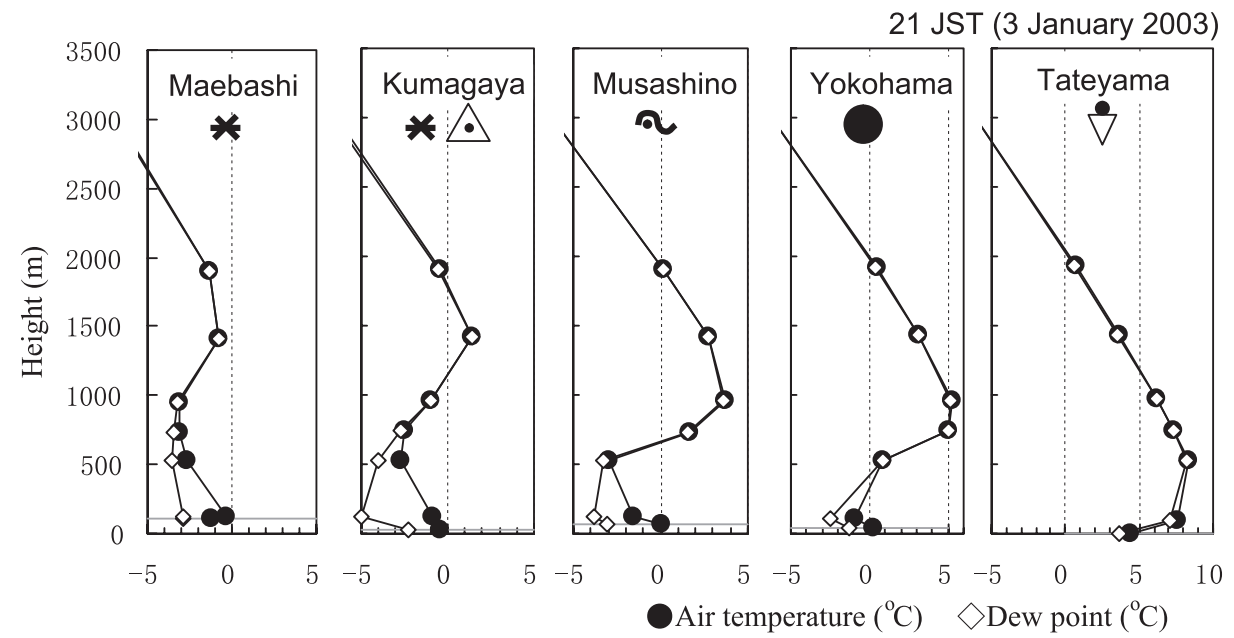

Fig. 10. Vertical profiles of air temperature and dew point temperature obtained from the mesoscale objective analysis data, and precipitation types observed at Maebashi, Kumagaya, Musashino, Yokohama, and Tateyama at 2100 JST on 3 January 2003. 
nearly saturated while the refreezing layer had a large difference between the air temperature and the dew point, so relatively dry air conditions existed in the inland region of the Kanto Plain. The precipitation types observed at the ground level are a consequence of this vertical atmospheric structure. In other words, the thermal atmospheric conditions applied to precipitation particles in the melting and refreezing layers determine whether freezing rain or ice pellets reach the ground.

We considered theoretically the thermodynamic conditions required for freezing rain and ice pellets to occur by referring to the 3 January case of the Kanto Plain. We defined the melting layer as an air layer in which the air temperature is above 0 ${ }^{\circ} \mathrm{C}$, and the refreezing layer as an air layer in which the air temperature is below $0^{\circ} \mathrm{C}$ and which exists below the melting layer. We examined the process of discriminating between freezing rain and ice pellets, focusing on the conditions within the melting and refreezing layers. This examination was based on the mean air temperatures $\left(\bar{T}_{\mathrm{m}}, \bar{T}_{f}\right)$, the mean relative humidities $\left(\overline{R H}_{m}, \overline{R H}_{f}\right)$, and the depths $\left(D_{m}\right.$, $D_{f}$ ) of the melting and refreezing layers (Fig. 1). These parameters can be calculated for each point by using mesoscale objective analysis data.

\subsection{Melting of snow particles}

According to the investigations of the melting process of snow particles conducted by Matsuo and Sasyo (1981a) and Mitra et al. (1990), melted liquid water on the surface of a snow particle flows into its interior. We consider the heat balance between snow particles and environmental air on a solid ice surface by assuming a spherical shape with radius $r_{s}$. The heat balance on the surface of the snow particle as expressed by Pruppacher and Klett (1997) is

$$
-4 \pi r_{s}^{2} \rho_{s} L_{m} \frac{d r_{s}}{d t}=4 \pi r_{s} k_{a} \bar{f}_{h} \Delta T+4 \pi r_{s} L_{s} D_{v} \bar{f}_{v} \Delta \rho_{v},
$$

where $\rho_{s}$ is the density of a snow particle with iceskeleton structure, $\Delta T$ and $\Delta \rho_{v}$ are the temperature and water vapor differences between the surface of the snow particle and the environmental air, $L_{m}$ and $L_{s}$ are the latent heats of melting and sublimation of ice, $k_{a}$ and $D_{v}$ are the thermal conductivity and coefficient for water vapor diffusion in the air, and $\bar{f}_{h}$ and $\bar{f}_{v}$ are ventilation coefficients for the heat and water vapor transfers. Equation (1) means that the transfer rate of latent heat caused by melting of a snow particle is equal to the rates of heat supplied by conduction and sublimation from the air around the snow particle. Any change in the mass of the snow particle caused by sublimation is neglected in this study.

The heat conductivity of air $k_{a}$ can be obtained by equation of Beard and Pruppacher (1971) for moist air, and the diffusivity of water vapor in the air $D_{v}$ is calculated using equation of Hall and Pruppacher (1976). The ventilation coefficients $\bar{f}_{h}$ and $\bar{f}_{v}$ for heat and water vapor transfers can be equal (Matsuo and Sasyo 1981a; Pruppacher and Klett 1997), so the ventilation coefficient $\bar{f}_{i}$, defined as $\bar{f}_{i} \equiv \bar{f}_{h} \approx \bar{f}_{v}$, was determined using equation of Hall and Pruppacher (1976) for water vapor transfer on the surface of ice particles.

Although the density of snow particles influences the melting process, the density $\rho_{s}$ used in this study was the $0.030 \mathrm{~g} \mathrm{~cm}^{-3}$ value obtained from measurements made by Matsuo and Sasyo (1981a) and Ishizaka (1995). The radius of the snow particle $r_{s}$ is calculated based on the density of a snow particle with ice-skeleton structure $\rho_{s}$ and the radius of a melted liquid water droplet $r_{w}(=1 \mathrm{~mm})$, used as the radius of the ice pellets observed in Musashino City (Fig. 4).

Rewriting Eq.(1) focusing on the rate of decrease of the radius of the snow particle $r_{s}$ gives

$$
\frac{d r_{s}}{d t}=-\frac{\bar{f}_{i}}{r_{s} \rho_{s} L_{m}}\left(k_{a} \Delta T+L_{s} D_{v} \Delta \rho_{v}\right) .
$$

Substituting the mean air temperature $\bar{T}_{m}$ and mean water vapor $\bar{\rho}_{v, m}$ obtained from the mean relative humidity $\overline{R H}_{m}$ in the melting layer for Eq.(2) gives the rate of decrease of the radius due to melting, using calculations with a time step of 0.1 second. The time was defined to be the time necessary for complete melting of the snow particle $t_{m}$ as the radius of the snow particle $r_{s}$ approaches 0 . In this calculation, we assumed that the temperature on surface of the snow particle is $0^{\circ} \mathrm{C}$.

The depth of melting layer required for complete melting of the snow particle $D_{m}$ can be obtained from the time for complete melting $t_{m}$ and the fall velocity $U_{i}$ of snow particles:

$$
D_{m}=t_{m} U_{i} .
$$

The fall velocity of snow particles $U_{i}$ expressed by Böhm (1989) was used in this study. 


$$
U_{i}=\frac{R_{e} \eta_{a}}{2 \rho_{a}}\left(\frac{\pi}{A_{i}}\right)^{1 / 2}
$$

Here, $R_{e}$ is the Reynolds number, $\eta_{a}$ the air viscosity, $\rho_{a}$ the density of the air, and $A_{i}$ the crosssectional area of a snow particle in the direction of its fall (i.e., $A_{i}=\pi r_{s}^{2}$ ). The air viscosity $\eta_{a}$ can be calculated using the relationship with air temperature provided by Pruppacher and Klett (1997).

The mean air temperature $\bar{T}_{m}$, mean relative humidity $\overline{R H}_{m}$, and depth $D_{m}$ as the snow particle completely melts can be given from Eqs. (2), (3), and (4). Figure11 compares these parameters of the theoretical results for the complete melting of a snow particle and those of the melting layer over each point where precipitation types were

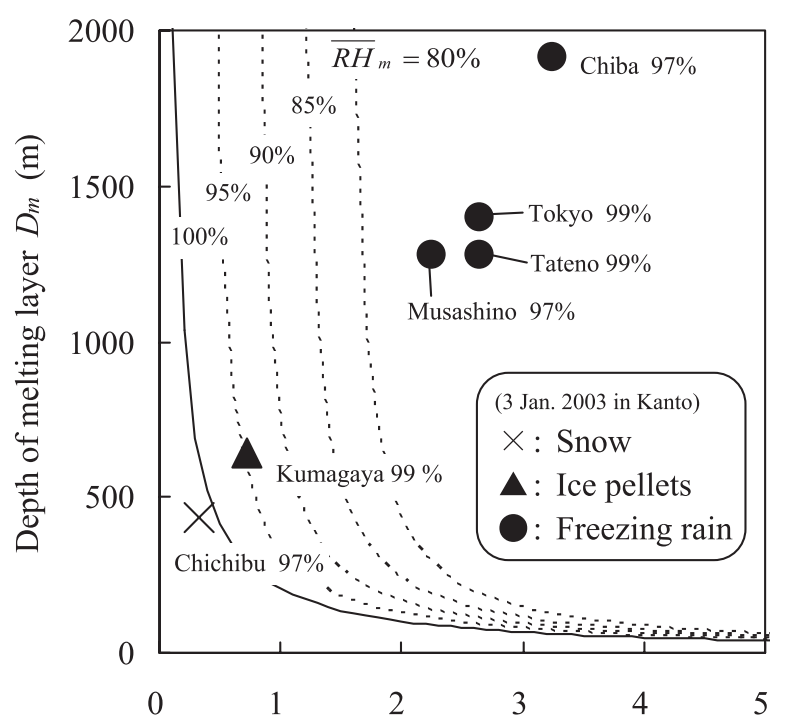

Mean temperature of melting layer $\overline{T_{m}}\left({ }^{\circ} \mathrm{C}\right)$

Fig. 11. Comparison of mean air temperature, mean relative humidity, and depth of melting layer for complete melting of snow particles with precipitation types observed at each station at 2100 JST on 3 January. The solid line represents the condition for complete melting at relative humidity of $100 \%$, and broken lines represent the conditions as relative humidities from $95 \%$ to $80 \%$ at $5 \%$ intervals. The calculations were carried out for snow particles with a melted radius of $1 \mathrm{~mm}$, corresponding to the ice pellets observed at Musashino City. observed at 2100 JST on 3 January. The lines corresponding to various values of $\overline{R H}_{m}$ in Fig. 11 discriminate between complete melting (above the lines) and partial or no melting (below the lines) of snow particles. The observed freezing rain and ice pellets are plotted on the complete melting side, and snow would have been observed with a partial or no melting state. Because occurrences of freezing rain and ice pellets require complete melting of snow particles, we defined the condition in Fig. 11 as a first diagnosis for the occurrence of freezing rain and ice pellets.

\subsection{Freezing of raindrops}

As raindrops freeze, an initial nucleation that lasts a relatively short time occurs with a fraction $\left(1-c_{w} \Delta T / L_{m}\right)$ of the water volume yet to freeze, and the raindrop will be heated to temperature close to $0^{\circ} \mathrm{C}$ due to the release of latent heat (Pruppacher and Klett 1997), where $c_{w}$ is the specific heat of water. We assumed that raindrops begin to freeze at the spherical surface, resulting in an internal liquid water part with radius $r_{w}$ and a spherical ice envelopment with radius $r_{i}$. The heat balance between the raindrop and the environmental air at the ice surface of the raindrop is expressed as

$$
\begin{aligned}
& 4 \pi r_{w}^{2} \rho_{w} L_{m} \frac{d r_{w}}{d t}\left(1-\frac{c_{w} \Delta T}{L_{m}}\right) \\
& =4 \pi r_{i} k_{a} \bar{f}_{h} \Delta T+4 \pi r_{i} L_{s} D_{v} \bar{f}_{v} \Delta \rho_{v}
\end{aligned}
$$

by Pruppacher and Klett (1997), where $\rho_{w}$ is the density of liquid water. The left-hand side of Eq.(5) represents the rate of release of latent heat due to freezing, and the right-hand side is the rate of heat loss to the environmental air due to conduction and sublimation. The mass change of the raindrops due to sublimation and increase in volume due to freezing of liquid water part were neglected in this study.

As in Section $4.2, k_{a}$ and $D_{v}$ were given, and the ventilation coefficients for raindrops were defined as $\overline{f_{w}} \equiv \bar{f}_{h} \approx \bar{f}_{v}$ and were obtained using equation of Pruppacher and Klett (1997) for water vapor transfer on the surface of liquid water droplets.

Rewriting Eq.(5), the rate of decrease of the radius of the liquid water part of a freezing raindrop is expressed as follows: 


$$
\frac{d r_{w}}{d t}=\frac{\bar{f}_{w} r_{i}}{\rho_{w} L_{m} r_{w}^{2}\left(1-c_{w} \Delta T / L_{m}\right)}\left(k_{a} \Delta T+L_{s} D_{v} \Delta \rho_{v}\right) .
$$

The envelopmental radius $r_{i}$ of a raindrop, that equals to the initial radius of liquid water part $r_{w 0}$, is $1 \mathrm{~mm}$ from ice pellets observed at Musashino City. Substituting the mean air temperature $\bar{T}_{f}$ and the mean water vapor $\bar{\rho}_{v, f}$, based on the mean relative humidity $\overline{R H}_{f}$ of the refreezing layer, into Eq.(6) gives the rate of decrease of the radius of the liquid water part due to freezing using calculations with a time step of 0.1 second. As $r_{w}$ reaches 0 , we consider that the raindrop has been completely frozen, and the time $t_{f}$ is defined as the time necessary for the complete freezing of a raindrop. The temperature on the surface of the raindrop was assumed to be $0^{\circ} \mathrm{C}$, and the function $1-c_{w} \Delta T / L_{m}$ was considered only at the initial time at which the raindrop began to freeze.

The depth of the refreezing layer required for complete freezing of a raindrop $D_{f}$ is given from the freezing time $t_{f}$ and the fall velocity $U_{w}$ of the raindrop.

$$
D_{f}=t_{f} U_{w}
$$

The fall velocity of raindrop $U_{w}$ can be estimated by using an equation from Atlas et al. (1973) as follow:

$$
U_{w}=\left\{965-1030 \exp \left(-12 r_{w}\right)\right\}\left(\frac{\rho_{a 0}}{\rho_{a}}\right)^{0.4},
$$

where $\rho_{a 0}$ and $\rho_{a}$ are the air density at $1013 \mathrm{hPa}$ and $20^{\circ} \mathrm{C}$ (Foote and Toit 1969) and the one at level of observation, respectively.

Equations (6), (7), and (8) give the relationship between the mean air temperature $\bar{T}_{f}$, the mean relative humidity $\overline{R H}_{f}$, and the depth $D_{f}$ of the refreezing layer required for the complete freezing of raindrops. In Fig. 12, the results are illustrated with precipitation types observed at each point at 2100 JST on 3 January. Solid (broken) lines in the figure indicate calculations for saturated (subsaturated) conditions. Above these lines, raindrops completely freeze and become ice pellets, whereas below these lines there is a partial or no freezing of the raindrops, resulting in freezing rain. In Fig. 12, these lines discriminate well between ice pellets and freezing rain. We defined the condition shown in Fig. 12 as a second diagnosis as to whether freezing rain or ice pellets had occurred.

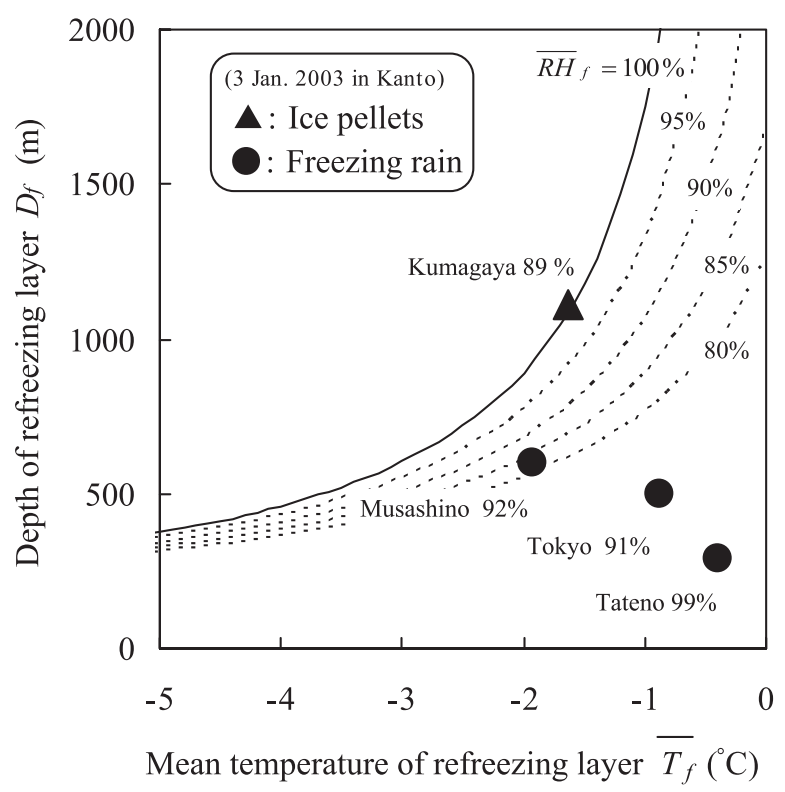

Fig. 12. The same as Fig. 11 except for complete freezing of raindrops.

\subsection{Conditions at the surface when freezing rain oc- curs}

The occurrence of freezing rain is also influenced by air temperature and humidity at ground level. For example, even if the air temperature is above $0^{\circ} \mathrm{C}$ at which raindrops would be warmed, a wet-bulb temperature below $0^{\circ} \mathrm{C}$ will maintain a supercooling state in the raindrops. Figure 13 indicates the air temperature and wet-bulb temperature at 15 meteorological observing stations in Japan, when freezing rain was observed over the past 14 winters (from November 1989 to April 2003). Most of the freezing rain was observed in an air temperature range of 0 to $-4^{\circ} \mathrm{C}$ except for a few cases in which the air temperature was above $0^{\circ} \mathrm{C}$. However, all freezing rain occurred in situations where the wet-bulb temperature was below 0 ${ }^{\circ} \mathrm{C}$. According to an investigation in North America conducted by Cortinas (2000), the occurrence ratio of freezing rain is about $70 \%$ with air temperatures below $0^{\circ} \mathrm{C}$, but it is $95 \%$ with dew points below $0^{\circ} \mathrm{C}$. As the air at the surface becomes subsaturated and the wet-bulb temperature or dew point temperature drops below $0^{\circ} \mathrm{C}$, a supercooling state will be maintained by evaporation in the raindrops in spite of air temperatures above $0^{\circ} \mathrm{C}$. To consider the effect of evaporation on the surface of raindrop, we used wet-bulb temperature at the ground level as the 


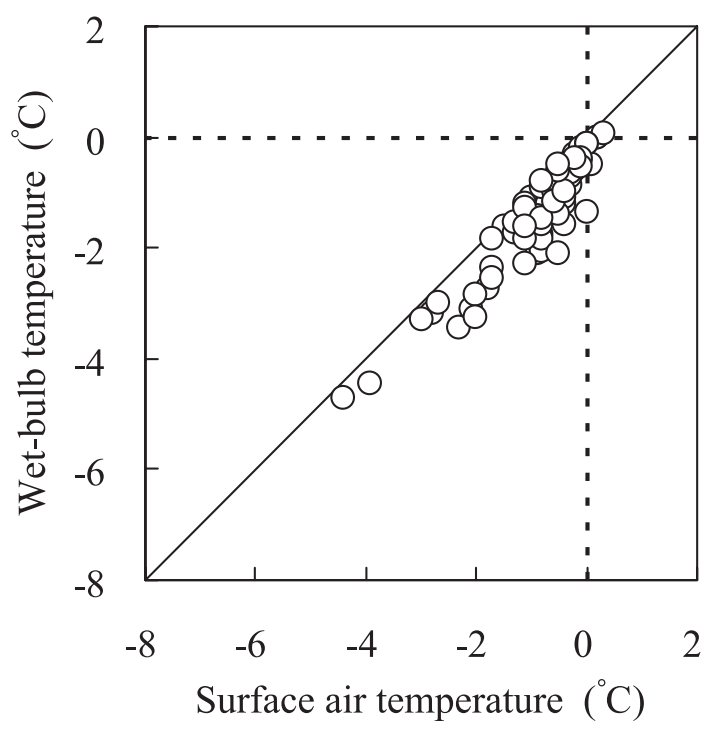

Fig. 13. Surface air temperature and wetbulb temperature at 15 meteorological observing stations in Japan, when freezing rain was observed over the past 14 winter seasons (November 1989-April 2003).

third discrimination factor between freezing rain and rain.

\subsection{Discriminating between freezing rain and ice pellets}

Using the three discrimination tests described above, precipitation types, including freezing rain and ice pellets at the surface, can be determined. Before the discrimination tests were carried out at each point to be analyzed, the presence of a melting layer in which the air temperature $\mathrm{T}>0^{\circ} \mathrm{C}$ and a refreezing layer in which $\mathrm{T}<0^{\circ} \mathrm{C}$ was verified using the mesoscale objective analysis data.

If both layers were present, the melting state of the snow particles and the freezing state of the raindrops were judged by the diagnosis methods in Fig. 11 and Fig. 12. In these algorithms, the ice pellets are assumed to reach the ground as completely melted snow particles and completely frozen raindrops. Freezing rain falls with the complete melting of snow particles and incomplete freezing of raindrops, with the wet-bulb temperatures at the ground level below $0^{\circ} \mathrm{C}$. In the case where there is only a melting layer near the surface, whether or not snow or rain will occur is determined by using the melting discrimination method in Fig. 11. Only snow will fall, as the air temperature is below $0^{\circ} \mathrm{C}$ at every upper level.

\subsection{Results of discrimination}

Figure 14 indicates the precipitation types estimated by the above method together with those observed at 2100 JST on 3 January in the Kanto Plain. Comparing the two distributions indicates that the precipitation types were well expressed and that a detailed distribution could be obtained by the discrimination methods examined in this study. Freezing rain would fall in a transition region between snow and rain, including stations at which the anemometer was frozen (Fig. 5), which occurred mainly in the western portion of the Kanto Plain. Ice pellets were estimated in the center of the freezing rain region, corresponding to the core of the cold air advection near the surface seen in Fig. 9.

\section{Discussion}

\subsection{Climatic characteristics of freezing rain and ice pellets in the Kanto Plain}

The effects of climatic features on freezing rain and ice pellet occurrences in the Kanto Plain were examined using surface meteorological data and precipitation types observed at each station over the past 14 winter seasons, from November 1989 to April 2003.

From these data, ice pellets have fallen somewhere on the Kanto Plain 50 times in the past 14 winters. The freezing rain and glaze phenomenon was not observed officially at the meteorological observing stations. However, the lack of wind observations due to frozen anemometers was recorded twice, on 15 January 1998 and 3 January 2003, and was accompanied by ice pellets in both cases.

The occurrence frequencies of ice pellet in winter (November-April) at each station are given in Fig. 15. Most of the ice pellets fell in Kumagaya, Tokyo, and Yokohama in the western portion of the Kanto Plain, similar to the case in Fig. 14. In particular, Tokyo and Kumagaya experienced ice pellets more than once during a winter.

Figure 16 indicates the surface distributions of the mean equivalent potential temperature, the mean relative humidity, and the most frequently observed wind direction when ice pellets were observed in Kumagaya, Tokyo, and Yokohama. The mean equivalent potential temperatures in this figure represent the difference between values in Tokyo and at each station. In Fig. 16, cold air with 

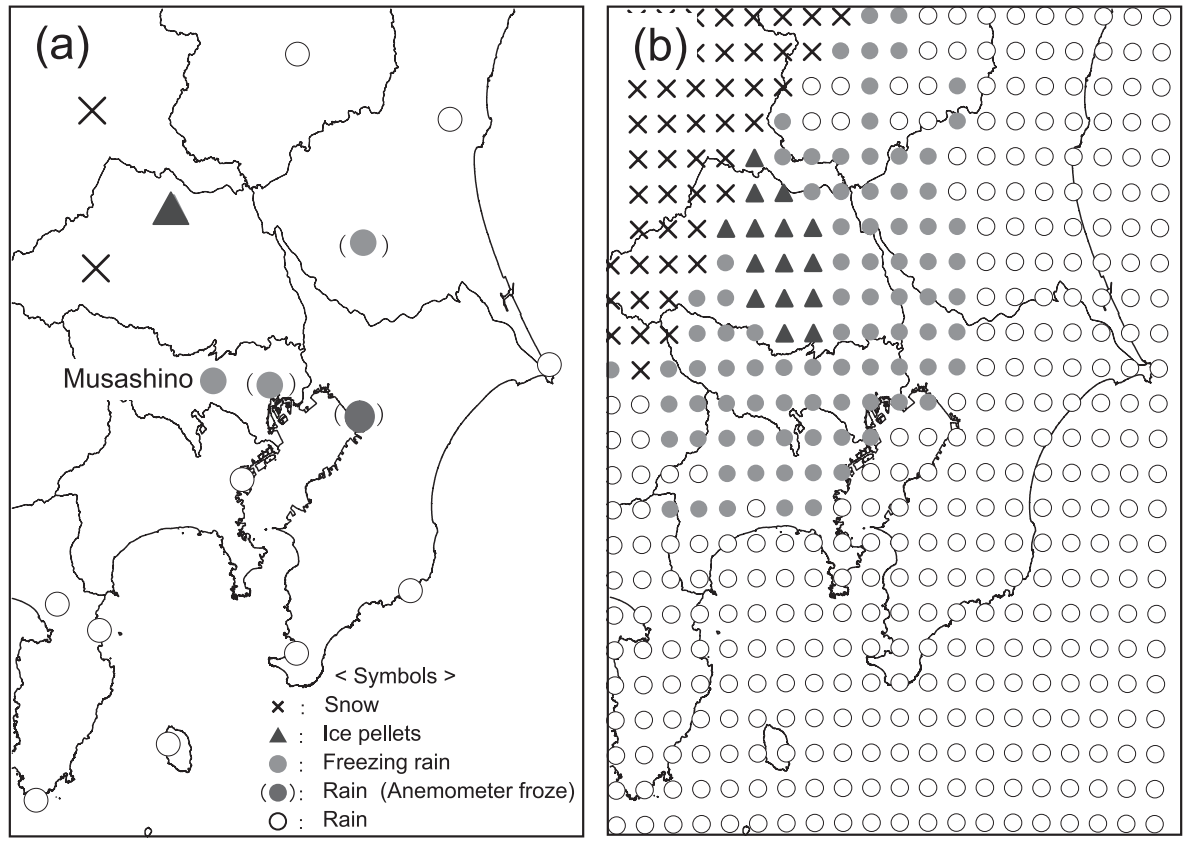

Fig. 14. Distributions of precipitation types that were (a) observed and (b) estimated at 2100 JST on 3 January 2003.

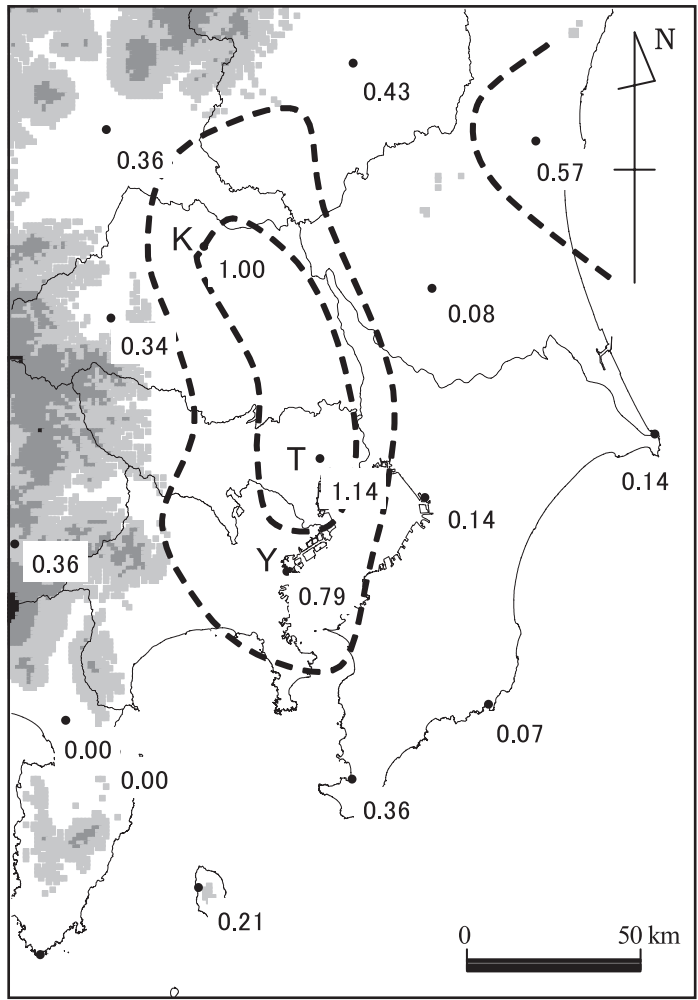

low relative humidity flows from the inland mountainous region to the southern coastal region along a geographical distribution, and the horizontal gradient of the equivalent potential temperature is consequently enhanced in the region between the inland and coastal areas. Comparing Fig. 16 with Fig. 15, the meteorological observing stations where ice pellets frequently occurred were located within a cold air advection. This feature was also confirmed for the event of 3 January 2003, as seen in Fig. 9.

Most ice pellets have been observed accompanied by synoptic low moving along the south coast of Japan as seen in Fig. 6. According to Fujibe (1990), northwesterly cold and dry flows from the inland region near the surface constitute the characteristic wind pattern in the Kanto Plain whenever synoptic low passes along the south of the plain.

Fig. 15. Occurrence frequency of ice pellets in the Kanto Plain over the past 14 winter seasons (November 1989-April 2003). The unit of frequency is the number of events per year, and its contours are shown with an interval of 0.5. The letters K, T, and Y denote Kumagaya, Tokyo, and Yokohama. 


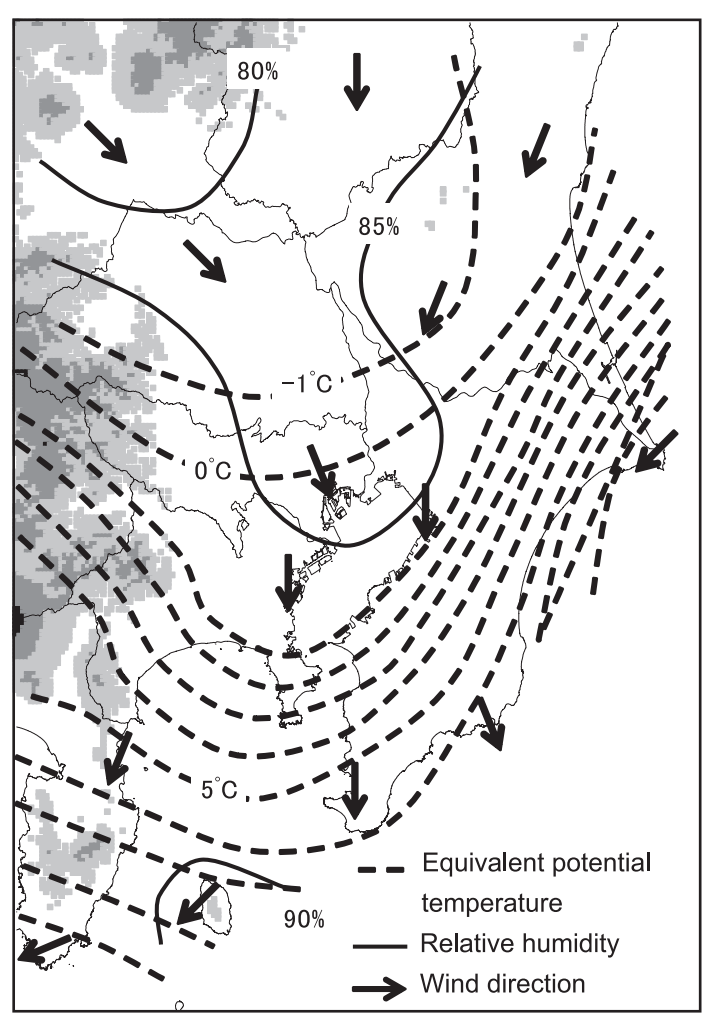

Fig. 16. Distribution of mean equivalent potential temperature, mean relative humidity, and most frequent wind direction when ice pellets were observed at the stations of Kumagaya, Tokyo, and Yokohama. Solid lines denote the relative humidity contours at $5 \%$ intervals, while broken lines denote the deviation of equivalent potential temperature from the value for Tokyo.

Observation of the cold air advection by Seino et al. (2003) demonstrated that this advection consists of a stable layer about $400 \mathrm{~m}$ thick. Moreover, cold air advection begins to occur in the western portion of the Kanto Plain, mainly at night, due to the convergence of drainage flows from mountain slopes in the northern and western parts of the plain (Kondo 1995; Seino et al. 2003). This is maintained even in daytime in spite of warm air advection provided by the synoptic low dominating the plain (Fujibe 1994; Seino et al. 2003).

In the Kanto Plain, cold air advection from inland mountainous regions to the area south of the plain tends to produce a refreezing layer near the surface, and warm air advection associated with synoptic low exists above this refreezing layer.
Therefore, the vertical structures required for ice pellets and freezing rain to occur are produced easily in the western portion of the Kanto Plain.

\subsection{Verification of the discrimination result}

The method of distinguishing freezing rain from ice pellets examined in this paper is based on an approximate calculation, using a hypothesis on the melting and freezing processes of precipitation particles and referring to only a single event in the Kanto Plain. The general applicability of this method will be verified using upper sounding data from the USA (Zerr 1997), because few events of freezing rain and ice pellets have occurred during upper air sounding at the meteorological stations in Japan.

Zerr (1997) determined the maximum air temperature and depth of the melting layer and the minimum air temperature and depth of the refreezing layer during many events of freezing rain and ice pellets, but the relative humidity was not investigated. The maximum and minimum air temperatures in the melting and refreezing layers were converted to mean air temperatures by a simple geometrical technique from Rauber et al. (2001b). Figure 17 compares the results of events shown by Zerr (1997) and the discrimination of freezing rain and ice pellets in this study.

Regarding the melting state in Fig. 17a, two cases of ice pellets are plotted below the discriminating line for a relative humidity of $100 \%$, meaning that the snow particles were not completely melted or that complete melting of snow particles with a radius of less than $1 \mathrm{~mm}$ had occurred. In general, ice pellets are also formed by the refreezing of partially melted snow particles (Stewart and King 1987; Zerr 1997; Thériault et al. 2006), but we neglected this process to find simple conditions for occurrences of freezing rain and ice pellets based on the 3 January event. Most of the freezing rain events, including cases with ice pellets, are well discriminated as having complete melting under near-saturated conditions, such as with a relative humidity of $100 \%$ or $95 \%$, a common feature of the melting layers examined by Bocchieri (1980).

Figure $17 \mathrm{~b}$ compares actual freezing rain and ice pellet events in the USA shown by Zerr (1997) with the discrimination for the freezing state of raindrops presented in this study. Because the relative humidity within the refreezing layer in events of Zerr (1997) is not known, the discriminating line for a relative humidity of $100 \%$ or $95 \%$ is 

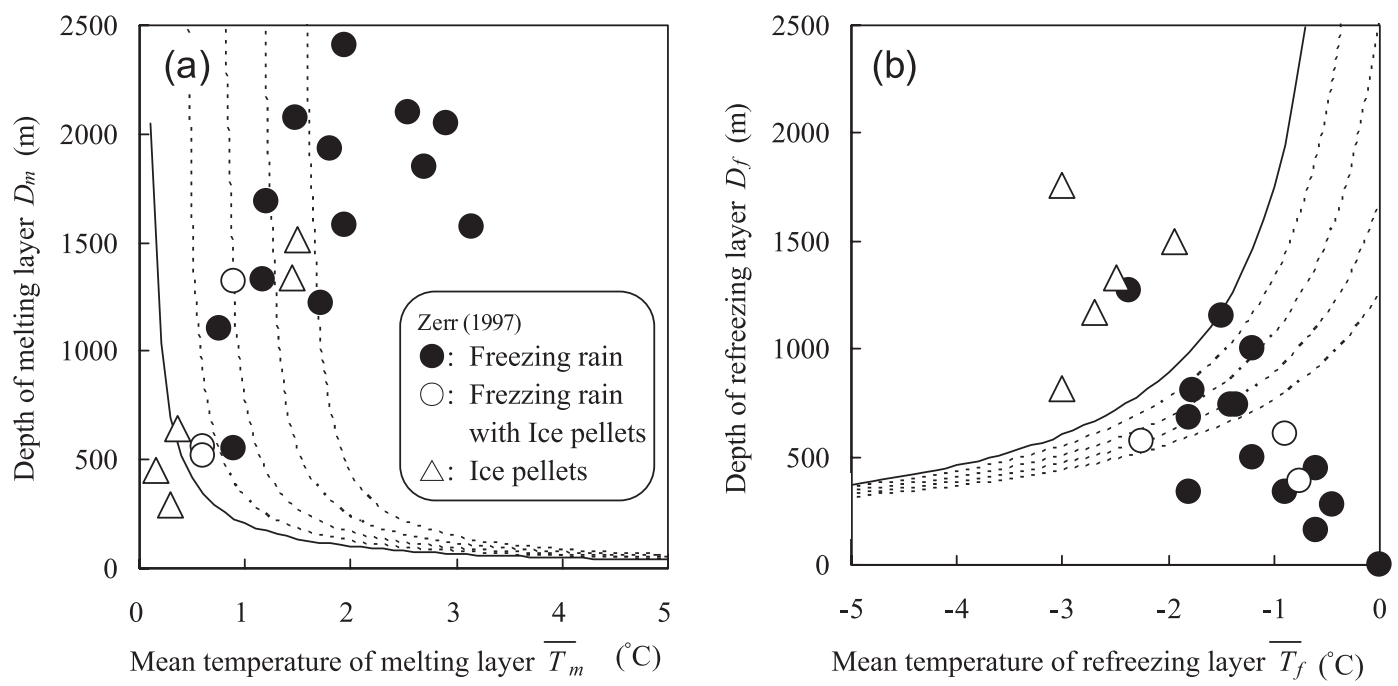

Fig. 17. Conditions required for (a) complete melting of snow particles and (b) complete freezing of raindrops in freezing rain and ice pellet events observed in the USA (Zerr 1997). Solid and broken lines are same as Fig. 11 and Fig. 12.

recognized as representing a near-saturated condition (Bocchieri 1980). Ice pellet and freezing rain events, including mixed cases, are well defined as having either complete or incomplete freezing of raindrops, except for a few freezing rain cases. In the actual event, a freezing nucleus is required for the freezing of liquid water drops. Although we assumed that raindrops begin to freeze immediately without freezing nucleus at the height where the air temperature is $0^{\circ} \mathrm{C}$, discrimination between freezing rain and ice pellets is made possible by using the conditions shown in Fig. 17b.

Beyond the discrimination methods discussed above, other sizes of precipitation particles should also be considered. The size distribution of water drops in the freezing rain has been measured by Iwai (1970), Stewart et al. (1990), and Crawford and Stewart (1995). These observations indicate that water drops with a radius of $1 \mathrm{~mm}$ observed in Musashino City are relatively large in freezing rain. Therefore, precipitation particles with radii smaller than $1 \mathrm{~mm}$ will melt and freeze more easily than in this study, and the discriminating conditions in Fig. 11 and Fig. 12 would be considered severe conditions for other freezing rain and ice pellet events. To improve the certainty of this method, validation of the method with observed data, such as different sizes of precipitation particles, should be accumulated in a future study. However, a combination of calculations for several precipitation particle radii using this discrimination method would result in detailed estimations corresponding to size distribution and mixture cases, such as freezing rain with ice pellets (Ozeki et al. 2006).

\section{Conclusions}

Based on the freezing rain and ice pellet event that occurred on 3 January 2003 in the Kanto Plain, Japan, the atmospheric conditions necessary for such phenomena have been investigated, and a diagnostic method for precipitation types, including freezing rain and ice pellets, was developed on a basis of thermodynamic theory. The results are as follows:

(1) Freezing rain and ice pellets fell mainly in the western portion of the Kanto Plain from 1800 JST to 2400 JST on 3 January. The ice pellets observed at Musashino City had a radius of $1 \mathrm{~mm}$.

(2) During the precipitation of the freezing rain and ice pellets, a northwesterly cold air advection near the surface dominated in the western portion of the Kanto Plain, and a southerly warm air advection at around $900 \mathrm{hPa}$ associated with a synoptic low was present over the plain.

(3) These atmospheric structures produced the conditions required for freezing rain and ice pellets: a melting layer to change snow particles to raindrops, and a refreezing layer to cool the raindrops into a supercooled state or to freeze them and form ice pellets. 
(4) Using the mean air temperatures, mean relative humidities, and depths of the melting and refreezing layers makes it possible to distinguish the environmental conditions required for freezing rain and ice pellets to form.

(5) In addition, distinguishing whether the wetbulb temperature at the surface was above or below $0^{\circ} \mathrm{C}$ was used to discriminate between rain and freezing rain.

(6) For the precipitation particles with an equivalent water radius of $1 \mathrm{~mm}$ observed at Musashino City, the distribution of precipitation types at 2100 JST on 3 January was estimated using the method described above. Close agreement was shown between the estimated and observed distributions of precipitation types, including the freezing rain and ice pellets.

\section{Acknowledgments}

We would like to thank two referees who have contributed constructive and valuable comments that have helped to improve the quality of this paper. The authors are also grateful to the editor, Dr. Masataka Murakami, for his helpful suggestions in improving the English expression used. The paper is based on a study by Matsushita, one of the authors, when he was a doctoral student at the Graduate School of Science and Technology, Chiba University. We are also much obliged to our coworkers at the university.

\section{References}

Atlas, D., R.C. Srivastava, and R.S. Sekon, 1973: Doppler radar characteristics of precipitation at vertical incidence. Rev. Geophys. Space Phys., 11, 1-35.

Beard, K.V. and H.R. Pruppacher, 1971: A wind tunnel investigation of the rate of evaporation of small water drops falling at terminal velocity in air. $J$. Atmos. Sci., 28, 1455-1464.

Bernstein, B.C., 2000: Regional and local influences on freezing drizzle, freezing rain, and ice pellet events. Wea. Forecasting, 15, 485-508.

Bocchieri, J.R., 1980: The objective use of upper air soundings to specify precipitation type. Mon. Wea. Rev., 108, 596-603.

Böhm, H.P., 1989: A general equation for the terminal fall speed of solid hydrometeors. J. Atmos. Sci., 46, 2419-2427.

Bourgouin, P., 2000: A method to determine precipitation types. Wea. Forecasting, 15, 583-592.

Changnon, S.A. and T.R. Karl, 2003: Temporal and spatial variations of freezing rain in the contiguous United States: 1948-2000. J. Appl. Meteor., 42, 1302-1315.
Cober, S.G., J.W. Strapp, and G.A. Isaac, 1996: An example of supercooled drizzle drops formed through a collision-coalescence process. J. Appl. Meteor., 35, 2250-2260.

Cortinas, J., Jr., 2000: A climatology of freezing rain in the Great Lakes region of North America. Mon. Wea. Rev., 128, 3574-3588.

Cortinas, J.V., Jr., B.C. Bernstein, C.C. Robbins, and J.W. Strapp, 2004: An analysis of freezing rain, freezing drizzle, and ice pellets across the United States and Canada: 1976-90. Wea. Forecasting, 19, 377-390.

Crawford, R.W. and R.E. Stewart, 1995: Precipitation types characteristics at the surface in winter storms. Cold Reg. Sci. Technol., 23, 215-229.

Czys, R.R., R.W. Scott, K.C. Tang, R.W. Przybylinski, and M.E. Sabones, 1996: A physically based, nondimensional parameter for discriminating between locations of freezing rain and ice pellets. Wea. Forecasting, 11, 591-598.

Foote, G.B. and P.S. Du Toit, 1969: Terminal velocity of raindrops aloft. J. Appl. Meteor., 8, 249-253.

Fujibe, F., 1990: Surface wind systems and cold airmasses in central Honshu during short-term precipitation events. Tenki, 37, 843-852 (in Japanese).

Fujibe, F., 1994: Diurnal variability of surface wind fields in the Kanto Plain during the passage lows in the Sea of Japan in winter. Tenki, 41, 321-330 (in Japanese).

Hall, W.D. and H.R. Pruppacher, 1976: The survival of ice particles falling from cirrus clouds in subsaturated air. J. Atmos. Sic., 33, 1995-2006.

Huffman, G.J. and G.A. Norman Jr., 1988: The supercooled warm rain process and the specification of freezing precipitation. Mon. Wea. Rev., 116, 2172-2182.

Hux, J.D., P.C. Knappenberger, P.J. Michaels, P.J. Stenger, H.D. Cobb, and M.P. Rusnak, 2001: Development of a discriminant analysis mixed precipitation (DAMP) forecast model for midAtlantic winter storms. Wea. Forecasting, 16, 248 -259 .

Ishihara, K. and Y. Tadokoro, 1990: Meteorological analysis of glaze occurrence in Japan. Proceedings, 5th International Workshop on Atmospheric Icing of Structures, Tokyo, A1-6-(1)-A1-6-(4).

Ishizaka, M., 1995: Measurement of falling velocity of rimed snowflakes. J. Japan. Soc. Snow and Ice, 57, 229-238 (in Japanese with English abstract).

Iwai, K., 1970: Size distributions of raindrops fallen as surface temperature below $0^{\circ} \mathrm{C}$. Bull. Inst. of Natural Educ., Shiga Heights, Shinshu Univ., 9, 93-99 (in Japanese).

Kondo, H., 1995: The thermally induced local wind and surface inversion over the Kanto Plain on calm winter nights. J. Appl. Meteor., 34, 1439-1448. 
Matsuo, T. and Y. Sasyo, 1981a: Empirical formula for the melting rate of snowflakes. J. Meteor. Soc. Japan, 59, 1-9.

Matsuo, T. and Y. Sasyo, 1981b: Melting of snow flakes below freezing level in the atmosphere. J. Meteor. Soc. Japan, 59, 10-25.

Matsushita, H. and F. Nishio, 2004: Climatological characteristics and local influences on occurrence of freezing precipitation in Japan. J. Japan. Soc. Snow and Ice, 66, 541-552 (in Japanese with English abstract).

Meisinger, C.L., 1920: The precipitation of sleet and the formation of glaze in the eastern United States, January 20 to 25 , 1920, with remarks on forecasting. Mon. Wea. Rev., 48, 73-80.

Mitra, S.K., O. Vohl, M. Ahr, and H.R. Pruppacher, 1990: A wind tunnel and theoretical study of the melting behavior of atmospheric ice particles. IV: Experiment and theory for snow flakes. J. Atmos. Sci., 47, 584-591.

Okada, T., 1914: Notes on the formation of glazed frost. Mon. Wea. Rev., 42, 284-286.

Ozeki, T., H. Matsushita, and F. Nishio, 2006: Field studies and mesoscale analysis of the precipitation icing events in Hokkaido on February 2223, 2004. J. Japan. Soc. Snow and Ice, 68, 409-420 (in Japanese with English abstract).

Pruppacher, H.R. and J.D. Klett, 1997: Microphysics of clouds and precipitation. Kluwer Academic Publishers, Dordrecht, Netherlands, 954 pp.

Rauber, R.M., L.S. Olthoff, M.K. Ramamurthy, and K.E. Kunkel, 2000: The relative importance of warm rain and melting processes in freezing precipitation events. J. Appl. Meteor., 39, 1185-1195.

Rauber, R.M., L.S. Olthoff, M.K. Ramamurthy, D. Miller, and K.E. Kunkel, 2001a: A synoptic weather pattern and sounding-based climatology of freezing precipitation in the United States East of the Rocky Mountains. J. Appl. Meteor., 40, 17241747.

Rauber, R.M., L.S. Olthoff, M.K. Ramamurthy, and K.E. Kunkel, 2001b: Further investigation of a physically based, nondimensional parameter for discriminating between locations of freezing rain and ice pellets. Wea. Forecasting, 16, 185-191.

Robbins, C.C. and J.V. Cortinas Jr., 2002: Local and synoptic environments associated with freezing rain in the contiguous United States. Wea. Forecasting, 17, 47-65.

Seino, N., H. Yoshikado, F. Kobayashi, J. Sato, and Members of Tsukuba area precipitation studies, 2003: Vertical structure of local fronts observed in Kanto, Japan. J. Meteor. Soc. Japan, 81, 367391.

Stewart, R.E. and P. King, 1987: Freezing precipitation in winter storms. Mon. Wea. Rev., 115, 12701279.

Stewart, R.E., R.W. Crawford, N.R. Donaldson, T.B. Low, and B.E. Sheppard, 1990: Precipitation and environmental conditions during accretion in Canadian East Coast winter storms. J. Appl. $\mathrm{Me}$ teor., 29, 525-538.

Thériault, J.M., R.E. Stewart, J.A. Milbrandt, and M.K. Yau, 2006: On the simulation of winter precipitation types. J. Geophys. Res., 111, D18202, doi: 10.1029/2005 JD006665.

Ushiyama, M., 1991: Basic consideration on the glaze phenomenon -A case of Nagano Prefecture in Japan-. Ann. Rep. Geography Nagano Pref., 9, 1827 (in Japanese).

Zerr, R.J., 1997: Freezing rain: An observational and theoretical study. J. Appl. Meteor., 36, 1647-1661. 